\title{
Shear behavior of concrete beams reinforced exclusively with longitudinal GFRP bars: analytical model
}

Hadi Baghi ${ }^{1}$, Joaquim A.O. Barros ${ }^{2}$, Monika Kaszubska ${ }^{3}$, Renata Kotynia ${ }^{4}$

${ }^{1}$ Post-doc, Department of Civil and Environmental Engineering, Wayne State University, Detroit, MI, U.S., e-mail: hadibaghi@gmail.com

${ }^{2}$ Full Professor, ISISE, Department of Civil Engineering, University of Minho, 4800-058, Guimarães, Portugal, e-mail: barros@civil.uminho.pt

${ }^{3} \mathrm{PhD}$ student, Faculty of Civil Engineering, Architecture and Environmental Engineering, Lodz University of Technology

Al. Politechniki 6, 90-924 Lodz, Poland, e-mail: monika.dymecka@p.lodz.pl

${ }^{4}$ Associate Professor, Faculty of Civil Engineering, Architecture and Environmental Engineering, Lodz University of Technology

Al. Politechniki 6, 90-924 Lodz, Poland, e-mail: renata.kotynia@p.lodz.pl

\begin{abstract}
A design approach based on the simplified modified compression field theory, but with the advantage of do not requiring an iterative procedure, is proposed for evaluating the shear capacity of beams do not including shear reinforcement. This model is capable of simulating beams flexurally reinforced with steel and fiber reinforced polymer (FRP) systems. To appraise the predictive performance of the proposed model a Data Base (DB) composed of 215 reinforced concrete beams without shear reinforcement is set. By applying the model to this DB, an average value for $V_{\text {exp. }} / V_{\text {ana. }}$ of 1.05 with a COV of $24 \%$ are obtained, where $V_{\text {exp. }}$ and $V_{\text {ana. }}$ are the shear capacity registered experimentally and obtained with the model, respectively. By applying the approach proposed by ACI Building Code to the data base, average and COV
\end{abstract}


values of 0.91 and $42 \%$ are determined, revealing the higher predictive performance of the proposed model. This was even higher in the beams flexurally reinforced with FRP systems, since the proposed model conducted to average and the COV values of 1.0 and $22 \%$, while 0.76 and $32 \%$ were obtained with the ACI approach. When proposed model was applied to the beams tested in the experimental program carried out, an average and COV values of 1.02 and $5.23 \%$ were determined.

Keynotes: Reinforced concrete beam; GFRP flexural reinforcement; shear failure; simplified modified compression field theory; sensitivity analysis.

\section{INTRODUCTION}

The development of a relatively simple design approach for predicting the shear capacity of reinforced concrete (RC) beams with good accuracy is still a challenging topic due to several and complex resisting mechanisms involved in shear such as: i) shear resistance assured by the uncracked concrete in the compression zone; ii) interface shear transfer by aggregate interlocking in the cracked concrete; iii) dowel action of the longitudinal reinforcement; and iv) resistance provided by transverse reinforcement, when existing [1].

There are two main approaches to predict shear strength of RC beams with and without shear reinforcement: the modified compression field theory (MCFT), and the truss model. There are two assumptions in the truss model: i) the diagonal compression struts are 45 degrees before and after cracking of concrete, ii) the concrete tensile strength in negligible. Hence, the truss model gives conservative values for shear strength of RC beams. ACI Building Code [2] is based on the truss model, by assuming the inclination of the critical diagonal crack (CDC) at 45 degrees, and considering the cracked concrete can contribute for the shear

capacity. Based on the ACI Building Code [2], nominal shear strength, $V_{n}$, of a RC beam is the addition of the shear resisting mechanisms provided by concrete and transverse reinforcement (if present): 


$$
V_{n}=V_{c}+V_{s}=0.17 \sqrt{f_{c}^{\prime}} b_{w} d+\frac{A_{s t} f_{s t, y}}{s} d
$$

where $f_{c}^{\prime}$ is the concrete compressive strength, $b_{w}$ and $d$ are the width and effective depth of the beam's cross section, and $A_{s t}, f_{s t, y}$, and $s$ are the cross section area, yield stress, and horizontal distance of transverse reinforcement, respectively. As mentioned before, in ACI Building Code [2], The CDC is assumed inclined at an angle of 45 degrees regarding the beam's axis, therefore no accurate predictions are obtained if this condition is not accomplished.

The Modified Compression Field Theory (MCFT), originally proposed by Vecchio and Collins [3], offers an improvement in terms of its predictive capability and considers the variation of the inclination of the $\mathrm{CDC}$ and tensile resistance of cracked concrete. However, this procedure is iterative in nature and requires knowledge of a relatively high number of parameters. Bentz et al. [4] proposed a simplified version of MCFT, called by the acronym SMCFT. This model considers the tensile stress factor in the cracked concrete ( $\beta$ ), and the inclination of the diagonal compressive strut in the web of the section $(\theta)$ to find the shear strength of a section with, or without, transverse reinforcement. These authors applied this model to a Data Base (DB) formed by $102 \mathrm{RC}$ specimens, and an average ratio of experimental to the analytically predicted shear strength $\left(V_{\text {exp. }} / V_{\text {ana. }}\right)$ of 1.11 , with a COV of $13.0 \%$, were obtained. The SMCFT is not a straightforward design approach, since it requires an iterative procedure, which introduces extra difficulties in the design methodology.

The shear strength of glass fiber polymer (GRP) reinforced concrete beams have been investigated by different researchers [5-16]. Most of the research studied the effect of the GFRP reinforcement ratio and its stiffness on the shear strength [5,6]. Maranan et al. [16] investigated concrete beams reinforced with GFRP bars and stirrups. According to the results, the GFRP stirrups enhanced both the shear strength and deflection capacity of the beams. Bentz et al. [13] studied the size effect of the beam and the longitudinal reinforcement ratio on the shear capacity. Kaszubska et al. [5] investigated the influence of the flexural reinforcement ratio and its arrangement, and the dowel action mechanism, on the cracking process and 
shear capacity of concrete beams reinforced with GFRP bars failing in shear. The authors concluded that, although of equal GFRP reinforcement ratio, the beams reinforced with two layers of GFRP reinforcement have presented more extensive crack pattern and shear capacity than the beams with one layer, which was justified on the higher beneficial dowel effect this arrangement has ensured.

In this paper, a straightforward design approach is proposed to predict the shear capacity of RC beams without transverse reinforcement, where the iterative procedure required by SMCFT is eliminated. For this purpose, a sensitivity analysis is carried out for assessing the relative importance of each input parameter that affects the shear capacity of RC beams without transverse reinforcement according to the SMCFT. Based on the results, an equation is derived for $\beta$. To assess the predictive performance of the proposed model, a DB composed of 215 RC beams without transverse reinforcement is set, and the model's performance is appraised. The obtained results with the proposed approach are compared to the ones determined with ACI model.

\section{SIMPLIFIED MODIFIED COMPRESSION FIELD THEORY}

According to the SMCFT of Bentz et al. [4], the shear capacity of a RC beam $\left(V_{n}=v b_{w} d, b_{w}\right.$ and $d$ are width and effective depth of beam, respectively) is obtained by the following equation:

$$
v=v_{c}+v_{s}=\beta \cdot \sqrt{f_{c}^{\prime}}+\rho_{s t} \cdot f_{s t, y} \cdot \cot \theta
$$

where $v_{c}$ and $v_{s}$ are the shear strength provided by concrete and transverse steel reinforcement, respectively, being $\rho_{s t}$ the transverse steel reinforcement ratio. In this equation, $\beta$ and $\theta$ are the tensile stress factor in the cracked concrete and the inclination of the diagonal compressive strut in the beam's web, respectively. These parameters are obtained from the following equations:

$$
\begin{aligned}
& \beta=\frac{0.4}{1+1500 \varepsilon_{x}} \frac{1300}{1000+s_{x e}} \\
& \theta=\left(29+7000 \varepsilon_{\mathrm{x}}\right)\left(0.88+\frac{\mathrm{s}_{\mathrm{xe}}}{2500}\right) \leq 75^{\circ}
\end{aligned}
$$


where $s_{x e}$ represents the crack spacing, which can be obtained as follows:

$$
s_{x e}=\frac{35 s_{x}}{a_{g}+16} \geq 0.85 s_{x}
$$

In this equation, $s_{x}$ and $a_{g}$ are the vertical distance between longitudinal reinforcement and the maximum dimension of aggregates, respectively. The axial strain, $\varepsilon_{x}$, can be obtained from the following equation (limited to the yield strain, $\varepsilon_{l, y}$ ):

$$
\varepsilon_{x}=\frac{f_{l}}{E_{l}}=\frac{v \cot \theta-v_{c} / \cot \theta}{E_{l} \rho_{l}} \leq \varepsilon_{l, y}
$$

where $f_{l}, E_{l}$ and $\rho_{l}$ are the stress (limited to the yield stress, $f_{l, y}=E_{l} \varepsilon_{l, y}$ ), the modulus of elasticity, and the ratio of the longitudinal reinforcement, respectively. The procedure to calculate the shear strength of a RC beam, according to the SMCFT, is summarized as follows [1]:

Step 1: Input parameters;

Step 2: Assume a value for $\varepsilon_{x}$;

Step 3: Calculate the crack spacing using Eq. (5);

Step 4: Calculate $\beta$ and $\theta$ using Eq. (3) and Eq. (4), respectively;

Step 5: Calculate total shear stress based on Eq. (2);

Step 6: Calculate the longitudinal strain, $\varepsilon_{x}$, according to Eq. (6) and compare to the assumed $\varepsilon_{x}$ in Step

2. Repeat procedure until $\left|\varepsilon_{x}^{q+1}-\varepsilon_{x}^{q}\right| / \varepsilon_{l, y} \leq 10^{-6}$;

\section{SENSITIVITY ANALYSIS}

A sensitivity analysis is carried out to assess the relative importance of each input parameter on the shear capacity of RC beams without shear reinforcement. Sensitivity analysis means to investigate the effect of input parameters on the objective function. There are two different approaches to execute sensitivity analysis: local and global sensitivity analysis. Local sensitivity analysis evaluates the objective function by 
changing one parameter and keeping other parameters fixed, while global sensitivity analysis evaluates the objective function by changing all the parameters simultaneously. Global sensitivity analysis considers the influence of the interaction between parameters on the objective function [17], while this interaction is not considered in the local sensitivity analysis. Global sensitivity analysis is an appropriate option for sensitivity analysis of SMCFT due to the iterative nature of the model [1]. The Monte Carlo method is a process of running a model numerous times with a random selection of each input parameter simultaneously, therefore is considered a global sensitivity analysis, and was the one selected in the present work. All of the input parameters for a RC beam without shear reinforcement $\left(d, b_{w}, f_{c}^{\prime}, a_{g}, E_{l}, \rho_{l}\right)$ are characterized by a uniform probability distribution, which means a range of possible values with the same likelihood of occurrence (Table 1).

To measure the influence of each input parameter on the objective function, the following coefficient of correlation parameter, $r$, is used:

$$
r=\frac{n \sum_{i=1}^{n} x_{i} y_{i}-\left(\sum_{i=1}^{n} y_{i}\right)\left(\sum_{i=1}^{n} x_{i}\right)}{\sqrt{n\left(\sum_{i=1}^{n} x_{i}^{2}\right)-\left(\sum_{i=1}^{n} x_{i}\right)^{2}} \sqrt{n\left(\sum_{i=1}^{n} y_{i}^{2}\right)-\left(\sum_{i=1}^{n} y_{i}\right)^{2}}}
$$

where $n$ is the number of the samples, $x_{i}$ is the input parameter and $y_{i}$ is the output. The $r$ varies between -1 and +1 . Positive value of $r$ means a positive linear correlation, which indicates that the objective function $(y)$ increases with the input parameter $(x)$, and vice versa. A negative value of $r$ means a negative linear correlation, which indicates a decrease of $y$ with the increase of $x$, and an increase of $y$ with a decrease of $x$. And finally, when $r$ is closed to 0 it means that no linear correlation or a weak linear correlation exist [32]. According to these definitions, the influence of the input parameters $\left(d, b_{w}, f_{c}^{\prime}, a_{g}\right.$ , $E_{l}, \rho_{l}$ ) on Eq. (2) and $\beta$ for 100,000 samples are presented in Figure 1. The range of all variables provided in Table 1 cover the characteristics of all tested beams in Data Base. The obtained results demonstrate the $\rho_{l}$ has the highest influence on the shear capacity of this type of beams, with a favorable effect on the $v$ due to the dowel effect it provides. The effective depth of the beam's cross section, $d$, has 
also an important influence on the $v$, with a decrease of the beam's shear capacity with the increase of the $d$, which is the well-known size effect.

Based on the results presented in Figure 1, the relationship between $\beta$ vs. $\frac{\rho_{l} \times E_{l}}{f_{c}^{\prime}} \times\left(\frac{b_{w}}{d}\right)$ for 100,000 generated samples with Monte Carlo simulation is shown in Figure 2. This relationship does not consider the effect of the aggregate size due to the lack of enough information about this parameter in literature. This curve is defined by the following equation:

$$
\beta_{N}=0.07 \times x^{0.22} \quad 0.05<\beta_{N}<0.30
$$

where $x$ is $\frac{E_{l} \times \rho_{l}}{f_{c}^{\prime}} \times\left(\frac{b_{w}}{d}\right)$. The Sum of Squares due to Error (SSE), R-square, and Root Mean Squared Error (RMSE) for this fitted curve are 80, 0.93, and 0.02, respectively, which indicate the good fit of the model to the generated samples. More information about Goodness-of-Fit Statistics can be found in [1]. The $\beta_{N}$ can be implemented in the following equation to find the shear capacity of a RC beam without shear reinforcement.

$$
v=v_{c}=\beta_{N} \cdot \sqrt{f_{c}^{\prime}}
$$

\section{ASSESSMENT OF THE PREDICTIVE PERFORMANCE OF THE DEVELOPED MODEL}

A Data Base (DB) containing $215 \mathrm{RC}$ beams without transverse reinforcement was collected in [6] from published literature to appraise the predictive performance of the developed approach. This DB includes beams of different size, longitudinal reinforcement ratio, modulus of elasticity for the flexural reinforcement (steel and FRP bars), and concrete compressive strength [18].

All the beams in this DB failed in shear. The collected beams have the following characteristics: $90 \leq b_{w} \leq$ $460 \mathrm{~mm} ; 140 \leq d \leq 940 \mathrm{~mm} ; 2.4 \leq a / d \leq 17.0 ; 16 \leq f_{c}^{\prime} \leq 95 \mathrm{MPa}, 32 \leq E_{l} \leq 210 \mathrm{GPa}$, and $0.3 \% \leq \rho_{l} \leq$ $5.0 \%$. All the collected data is provided in Table 2, and its distribution in terms of these main parameters 
is presented in Figure 3. The DB contains values from experiments performed on 126 beams with steel and CFRP longitudinal reinforcement, and 89 beams with GFRP and AFRP longitudinal reinforcement.

For the new model and ACI Building Code [2] approach, the obtained values of $V_{\text {ana. }}=v_{\text {ana. }} b_{w} d$ are compared with $V_{\text {exp. }}$ of the $\mathrm{DB}$, and the values of the $\lambda$ factor corresponding to the $V_{\text {exp. }} / V_{\text {ana. }}$ ratio are included in Table 2 and represented in Figure 4. In all the comparisons carried out, average values for the material properties were considered, and no safety factors were taken, therefore approaches estimating $V_{\text {exp. }} / V_{\text {ana. }}$ closer to unitary value are those of higher predictive performance. The new model has assured an average value of $V_{\text {exp. }} / V_{\text {ana. }}$ of 1.05 for all the beams with a COV of $23.8 \%$, while ACI model has an average value of $V_{\text {exp. }} / V_{\text {ana. }}$ of 0.91 with a much higher $\operatorname{COV}(42 \%)$.

Figure 5 represents the $V_{\text {exp. }} / V_{\text {ana. }}$ of the beams with steel and FRP longitudinal reinforcement for the new and ACI models. The average value for the beams with FRP longitudinal reinforcement is 1.0 with a COV of $22 \%$ in the new model, while an average value of 0.76 with a COV of $32 \%$ were obtained in the ACI model. Average value of the beams with steel longitudinal reinforcement in the new model is 1.17 with a COV of $23 \%$, but these values are 1.35 and $27 \%$, respectively, for the ACI model. According to these results, it can be concluded that the proposed model has better accuracy than ACI model regardless the type of flexural reinforcement used in the beams.

The predictive performance of the adopted approaches is being detrimentally affected due to some abnormal results reported in some literature that conducted to the DB with 215 beams. Due to the suspicious that some problems have occurred in the experimental programs of these beams, the suspicious beams were removed from the $\mathrm{DB}$, resulting a reduced $\mathrm{DB}(\mathrm{RDB})$ of 145 beams. A RC beam was removed if:

a) showed very poor performance in both design models $\left(V_{\text {exp. }} / V_{\text {ana. }} \leq 0.85\right)$;

b) $a / d>10$ (high probability of has been failed in bending); 
c) $0.4 \%>\rho_{s l}>5.0 \%$ (abnormal high and low percentage of longitudinal reinforcement, probability of has been failed in bending and providing unrealistic dowel effect resisting mechanism, respectively);

The results of the RDB are presented in Figure 6. The new model has assured an average value of $V_{\text {exp. }} / V_{\text {ana. }}$ of 1.13 for RDB with a COV of $18 \%$. The ACI model has an average value of $V_{\text {exp. }} / V_{\text {ana. }}$ of 0.99 with COV of $34 \%$.

A modified version of the Demerit Points Classification (DPC) [19] proposed by Collins [20] is presented, where a penalty (PEN) is assigned to each range of $\lambda$ parameter according to Table 3 , and the performance of each approach is determined by the total of penalties (Total PEN).

According to the results included in Tables 4 and 5, the predictive performance of the proposed approach is better than of the ACI model in both $\mathrm{DB}$ and $\mathrm{RDB}$, since it has a large number of predictions in the appropriate safety and conservative intervals according to the DPC (Table 3). According to Table 4, the new approach has 173 samples in appropriate safety and conservative intervals, while ACI model only has 96 samples. The major difference between the new and the ACI models is in the dangerous and extremely dangerous intervals, since the proposed model has 41 samples in this interval, while ACI model has 116 samples. As can be observed from Figure 4 and Table 4, the new model outperforms the ACI model.

The model was also applied on the simulation of the shear capacity of the beams tested in the first part of this companion paper having been obtained an average value of 1.02 for the $V_{\text {exp. }} / V_{\text {ana. }}$ with a COV of $5.23 \%$.

\section{CONCLUSIONS}

An analytical model suitable for design practice was developed based on the Simplified Modified Compression Field Theory (SMCFT) for estimating the shear capacity of beams exclusively reinforced with flexural reinforcement (steel or FRP). By introducing an equation determined from sensitivity analysis, it was eliminated the iterative procedure required by the SMCFT. A Data Base (DB) constituted of 215 
reinforced concrete $(\mathrm{RC})$ beams, exclusively reinforced in bending, was set for assessing the predictive performance of the proposed model. Based on this DB, an average value of 1.05 with a COV of $23.8 \%$, were obtained for $V_{\text {exp. }} / V_{\text {ana. }}$ ( $V_{\text {exp. }}$ and $V_{\text {ana. }}$ are the experimental and analytical results, respectively), while using ACI model it was obtained 0.91 with a $\mathrm{COV}$ of $42 \%$, which indicates the better predictive performance of proposed model. When applied to the beams tested in the experimental program described in this work, an average value of 1.02 for the $V_{\text {exp. }} / V_{\text {ana. }}$ was obtained, with a COV of $5.23 \%$.

\section{ACKNOWLEDGEMENTS}

The second author wishes to acknowledge the grant SFRH/BSAB/114302/2016 provided by FCT. The support of the FCT through the project PTDC/ECM-EST/1882/2014 is acknowledged.

\section{REFERENCES}

1. Baghi, H., \& Barros, J. A. O. (2017). Design Approach to Determine Shear Capacity of Reinforced Concrete Beams Shear Strengthened with NSM Systems. Journal of Structural Engineering, 143(8). doi: 10.1061/(ASCE)ST.1943-541X.0001793

2. ACI Committee, A.C.I., \& International Organization for Standardization, Building code requirements for structural concrete (ACI 318-08) and commentary. 2011, American Concrete Institute.

3. Vecchio, F.J., Collins, M.P., "The Modified Compression-Field Theory for Reinforced Concrete Elements Subjected to Shear,” ACI Structural Journal, 1986: pp. 219-231.

4. Bentz, E. C., Vecchio, F. J., \& Collins, M. P. (2006). Simplified modified compression field theory for calculating shear strength of reinforced concrete elements. ACI Structural Journal, 103(4), 614624. doi: $10.14359 / 16438$

5. Kaszubskaa,M., Kotyniaa, R., Barrosb, J., (2017). Influence of longitudinal GFRP reinforcement ratio on shear capacity of concrete beams without stirrups. Journal of Procedia Engineering, 193, 
$361-368$.

6. R. Kotynia, M. Kaszubska M, Analysis of Concrete Contribution in the Shear Strength of Beams Reinforced with FRP / Steel Bars Without Stirrups, "fib Symposium 2016", Performance-Based Approaches for Concrete Structures, Proceedings.University of Cape Town, Cape Town, South Africa, 21-23 November 2016, Editor: Hans Beushausen

7. J.R.Yost, S.P.Gross, D.W.Dinehart and Associate Members.ASCE, Shear Strength Of Normal Strength Concrete Beams Reinforced With Deformed GFRP Bars, Journal of Composites for Construction, 5(4), 2001.

8. T. Alkhrdaji, A. Wideman, A. Belarbi, A. Nanni, Shear Strength of GFRP RC Beams and Slabs. Proc., CCC 2001.

9. A.K. El-Sayed, E.F. El-Salakawy, B. Benmokrane, Shear strength of fibre-reinforced polymer reinforced concrete deep beams without web reinforcement, Canadian Journal of Civil Engineering, 39,2012

10. F. Matta, A.K. El-Sayed, A. Nanni, B. Benmokrane, Size Effect on Concrete Shear Strength in Beams reinforced with Fiber-reinforced polymer bars, ACI Structural Journal, 110, 2013.

11. A.K. Tureyen, R.J. Forsch, Shear tests of FRP-reinforced concrete beams without stirrups, ACI Structural Journal, 99, 2002.

12. A.K. El-Sayed, E.F. El-Salakawy, B. Benmokrane, Shear capacity of high-strength concrete beams reinforced with FRP bars, ACI Structural Journal, 103(3), 2006.

13. Bentz, E.C., Massam, L., Collins, M.P., Shear Strength of Large Concrete Members with FRP reinforcement, Journal of Composites for Construction, 2010.

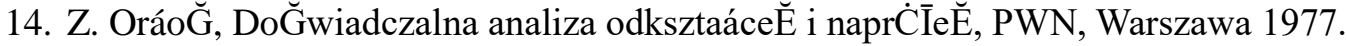

15. H.P.J. Taylor, Investigation of the Forces Carried Across Cracks in Reinforced Concrete Beams in Shear by Interlock of Aggregate. Technical Report 42.477, Cement and Concrete Association, London, England, 1970.

16. Maranan, G.B., Manalo, A., Benmokrane, B., Karunasena, W., Mendis, P., (2017). Shear Behavior 
of Geopolymer Concrete Beams Reinforced with Glass Fiber-Reinforced Polymer Bars. ACI Structural Journal, 114(2).

17. Gilman, J. R., Brickey, R. T., \& Red, M. M. (1998). Monte Carlo Techniques for Evaluating Producing Properties. SPE Rocky Mountain Regional/Low-Permeability Reservoirs Symposium. doi: $10.2118 / 39926-\mathrm{MS}$

18. Kotynia, R., \& Kaszubska, M. (2016). Analysis of Concrete Contribution in the Shear Strength of Beams Reinforced With FRP / Steel Bars Without Stirrups. In fib Symposium 2016 proceedings. Cape Town.

19. Moraes N. B., Barros, J., \& Melo, G. (2013). Model to Simulate the Contribution of Fiber Reinforcement for the Punching Resistance of RC Slabs. Journal of Materials in Civil Engineering, 26(7), doi: 10.1061/(ASCE)MT.1943-5533.0000913

20. Collins, M. P. (2001). Evaluation of Shear Design Procedures for Concrete Structures. Prepared for the CSA Technical Committee on Reinforced Concrete Design, Canada. 
Tables:

Table 1. Values characterizing the uniform probability distribution of the input parameters

\begin{tabular}{|c||c|c||c|c|c|c|}
\hline & $\begin{array}{c}d \\
(\mathrm{~mm})\end{array}$ & $\begin{array}{c}b_{w} \\
(\mathrm{~mm})\end{array}$ & $\begin{array}{c}f_{c}^{\prime} \\
(\mathrm{MPa})\end{array}$ & $\begin{array}{c}a_{g} \\
(\mathrm{~mm})\end{array}$ & $\begin{array}{c}E_{l} \\
(\mathrm{GPa})\end{array}$ & $\begin{array}{c}\rho_{l} \\
(\%)\end{array}$ \\
\hline $\begin{array}{c}\text { Range of } \\
\text { variation }\end{array}$ & $130-1200$ & $50-450$ & $15-100$ & $8-40$ & $30-250$ & $0.2-5$ \\
\hline
\end{tabular}


Table 2. Summary of experimental and analytical results applied to the DB

\begin{tabular}{|c|c|c|c|c|c|c|c|c|c|c|}
\hline Beam label & $\begin{array}{c}b_{w} \\
(\mathrm{~mm})\end{array}$ & $\begin{array}{c}d \\
(\mathrm{~mm})\end{array}$ & $a / d$ & $\begin{array}{c}f_{c}^{\prime} \\
(M P a)\end{array}$ & $\begin{array}{l}\rho_{l} \\
(\%)\end{array}$ & $\begin{array}{c}E_{l} \\
(G P a)\end{array}$ & $\begin{array}{c}V \\
(k N)\end{array}$ & $\beta_{N}$ & $\left(\frac{V_{\text {exp. }}}{V_{\text {ana. }}}\right)$ & $\left(\frac{V_{\text {exp. }}}{V_{\text {ana. }}}\right)_{A C I}$ \\
\hline 1Steel-a & 229 & 227 & 4.03 & 35 & 1.55 & 200 & 61 & 0.19 & 1.05 & 1.17 \\
\hline 1Steel-b & 229 & 227 & 4.03 & 35 & 1.55 & 200 & 56 & 0.19 & 0.98 & 1.08 \\
\hline 1Steel-c & 229 & 227 & 4.03 & 35 & 1.55 & 200 & 58 & 0.19 & 1.00 & 1.11 \\
\hline 1FRP-a & 229 & 225 & 4.06 & 35 & 1.10 & 40 & 39 & 0.12 & 1.05 & 0.76 \\
\hline 1FRP-b & 229 & 225 & 4.06 & 35 & 1.10 & 40 & 38 & 0.12 & 1.03 & 0.75 \\
\hline 1FRP-c & 229 & 225 & 4.06 & 35 & 1.10 & 40 & 37 & 0.12 & 0.98 & 0.71 \\
\hline 2FRP-a & 178 & 225 & 4.06 & 35 & 1.42 & 40 & 28 & 0.12 & 0.97 & 0.70 \\
\hline 2FRP-b & 178 & 225 & 4.06 & 35 & 1.42 & 40 & 35 & 0.12 & 1.20 & 0.87 \\
\hline 2FRP-c & 178 & 225 & 4.06 & 35 & 1.42 & 40 & 32 & 0.12 & 1.10 & 0.80 \\
\hline 3FRP-a & 229 & 225 & 4.06 & 35 & 1.65 & 40 & 40 & 0.13 & 0.98 & 0.78 \\
\hline 3FRP-b & 229 & 225 & 4.06 & 35 & 1.65 & 40 & 49 & 0.13 & 1.19 & 0.94 \\
\hline 3FRP-c & 229 & 225 & 4.06 & 35 & 1.65 & 40 & 45 & 0.13 & 1.09 & 0.87 \\
\hline 4FRP-a & 279 & 225 & 4.06 & 35 & 1.81 & 40 & 44 & 0.14 & 0.83 & 0.70 \\
\hline 4FRP-b & 279 & 225 & 4.06 & 35 & 1.81 & 40 & 46 & 0.14 & 0.87 & 0.73 \\
\hline 4FRP-c & 279 & 225 & 4.06 & 35 & 1.81 & 40 & 46 & 0.14 & 0.87 & 0.73 \\
\hline 5FRP-a & 254 & 224 & 4.08 & 35 & 2.00 & 40 & 38 & 0.14 & 0.78 & 0.66 \\
\hline 5FRP-b & 254 & 224 & 4.08 & 35 & 2.00 & 40 & 51 & 0.14 & 1.06 & 0.90 \\
\hline 5FRP-c & 254 & 224 & 4.08 & 35 & 2.00 & 40 & 47 & 0.14 & 0.97 & 0.82 \\
\hline 6FRP-a & 229 & 224 & 4.08 & 35 & 2.22 & 40 & 44 & 0.14 & 1.00 & 0.85 \\
\hline 6FRP-b & 229 & 224 & 4.08 & 35 & 2.22 & 40 & 42 & 0.14 & 0.96 & 0.81 \\
\hline 6FRP-c & 229 & 224 & 4.08 & 35 & 2.22 & 40 & 41 & 0.14 & 0.95 & 0.80 \\
\hline BM7 & 178 & 279 & 2.69 & 24 & 2.30 & 40 & 53 & 0.14 & 1.55 & 1.29 \\
\hline BM8 & 178 & 287 & 2.61 & 24 & 0.77 & 40 & 36 & 0.11 & 1.30 & 0.85 \\
\hline BM9 & 178 & 287 & 2.61 & 24 & 1.34 & 40 & 40 & 0.12 & 1.28 & 0.94 \\
\hline BR1 & 200 & 225 & 2.67 & 41 & 0.22 & 145 & 36 & 0.11 & 1.17 & 0.74 \\
\hline BR2 & 200 & 225 & 2.67 & 49 & 0.45 & 145 & 47 & 0.12 & 1.24 & 0.88 \\
\hline BR3 & 200 & 225 & 2.67 & 41 & 0.56 & 145 & 47 & 0.13 & 1.25 & 0.97 \\
\hline BR4 & 200 & 225 & 2.67 & 41 & 0.78 & 145 & 43 & 0.14 & 1.05 & 0.88 \\
\hline BA2 & 200 & 225 & 2.67 & 49 & 0.45 & 145 & 47 & 0.12 & 1.24 & 0.88 \\
\hline BA3 & 200 & 225 & 3.56 & 41 & 0.45 & 145 & 47 & 0.13 & 1.31 & 0.97 \\
\hline BA4 & 200 & 225 & 4.50 & 41 & 0.45 & 145 & 38 & 0.13 & 1.07 & 0.79 \\
\hline SN-1.7 & 250 & 326 & 3.10 & 44 & 1.73 & 200 & 145 & 0.17 & 1.55 & 1.58 \\
\hline CN-1.7 & 250 & 326 & 3.10 & 44 & 1.71 & 134 & 125 & 0.16 & 1.47 & 1.36 \\
\hline GN-1.7 & 250 & 326 & 3.10 & 44 & 1.71 & 42 & 78 & 0.12 & 1.18 & 0.85 \\
\hline SH-1.7 & 250 & 326 & 3.10 & 63 & 1.73 & 200 & 160 & 0.16 & 1.55 & 1.45 \\
\hline $\mathrm{CH}-1.7$ & 250 & 326 & 3.10 & 63 & 1.71 & 135 & 130 & 0.15 & 1.38 & 1.18 \\
\hline GH-1.7 & 250 & 326 & 3.10 & 63 & 1.71 & 42 & 87 & 0.11 & 1.19 & 0.79 \\
\hline SH-2.2 & 250 & 326 & 3.10 & 63 & 2.22 & 200 & 184 & 0.17 & 1.69 & 1.67 \\
\hline $\mathrm{CH}-2.2$ & 250 & 326 & 3.10 & 63 & 2.19 & 135 & 174 & 0.15 & 1.75 & 1.58 \\
\hline GH-2.2 & 250 & 326 & 3.10 & 63 & 2.19 & 42 & 116 & 0.12 & 1.50 & 1.05 \\
\hline Beam 1 & 150 & 168 & 3.97 & 29 & 0.45 & 38 & 13 & 0.10 & 0.91 & 0.54 \\
\hline Beam 3 & 150 & 212 & 3.14 & 29 & 0.71 & 32 & 18 & 0.10 & 1.00 & 0.60 \\
\hline Beam 5 & 150 & 263 & 2.53 & 29 & 0.86 & 32 & 25 & 0.10 & 1.16 & 0.69 \\
\hline Beam 7 & 150 & 168 & 3.97 & 50 & 1.35 & 32 & 18 & 0.11 & 0.89 & 0.58 \\
\hline Beam 9 & 150 & 212 & 3.14 & 50 & 1.07 & 32 & 28 & 0.10 & 1.23 & 0.72 \\
\hline Beam 11 & 150 & 263 & 2.53 & 50 & 1.15 & 32 & 30 & 0.10 & 1.12 & 0.63 \\
\hline SB40 & 150 & 224 & 3.35 & 43 & 1.35 & 207 & 45 & 0.16 & 1.28 & 1.20 \\
\hline GB43 & 150 & 223 & 3.36 & 40 & 1.28 & 45 & 27 & 0.12 & 1.11 & 0.75 \\
\hline TB6B & 150 & 220 & 3.49 & 95 & 1.30 & 45 & 29 & 0.10 & 0.94 & 0.53 \\
\hline S1-1 & 457 & 883 & 3.11 & 30 & 0.60 & 41 & 154 & 0.10 & 0.73 & 0.41 \\
\hline
\end{tabular}




\begin{tabular}{|c|c|c|c|c|c|c|c|c|c|c|}
\hline Beam label & $\begin{array}{c}b_{w} \\
(\mathrm{~mm})\end{array}$ & $\begin{array}{c}d \\
(\mathrm{~mm})\end{array}$ & $a / d$ & $\begin{array}{c}f_{c}^{\prime} \\
(M P a)\end{array}$ & $\begin{array}{c}\rho_{l} \\
(\%)\end{array}$ & $\begin{array}{c}E_{l} \\
(G P a)\end{array}$ & $\begin{array}{c}V \\
(k N)\end{array}$ & $\beta_{N}$ & $\left(\frac{V_{\text {exp. }}}{V_{\text {ana. }}}\right)$ & $\left(\frac{V_{\text {exp. }}}{V_{\text {ana. }}}\right)_{A C I}$ \\
\hline S3-1 & 114 & 294 & 3.11 & 60 & 0.60 & 41 & 15 & 0.08 & 0.76 & 0.35 \\
\hline S3-2 & 114 & 294 & 3.11 & 32 & 0.60 & 41 & 19 & 0.09 & 1.14 & 0.60 \\
\hline S3-3 & 114 & 294 & 3.11 & 32 & 0.60 & 41 & 18 & 0.09 & 1.07 & 0.56 \\
\hline S6-1 & 229 & 147 & 3.11 & 60 & 0.60 & 41 & 29 & 0.11 & 1.05 & 0.65 \\
\hline S6-2 & 229 & 147 & 3.11 & 32 & 0.60 & 41 & 37 & 0.12 & 1.60 & 1.13 \\
\hline S6-3 & 229 & 147 & 3.11 & 32 & 0.60 & 41 & 26 & 0.12 & 1.14 & 0.81 \\
\hline S1B-1 & 457 & 880 & 3.12 & 30 & 1.20 & 41 & 221 & 0.11 & 0.90 & 0.59 \\
\hline S1B-2 & 457 & 880 & 3.12 & 31 & 1.20 & 41 & 216 & 0.11 & 0.87 & 0.57 \\
\hline L05-0 & 450 & 937 & 3.26 & 46 & 0.51 & 37 & 135 & 0.08 & 0.58 & 0.28 \\
\hline M05-0 & 450 & 438 & 3.48 & 35 & 0.55 & 37 & 86 & 0.10 & 0.71 & 0.43 \\
\hline S05-0 & 450 & 194 & 3.93 & 35 & 0.66 & 37 & 55 & 0.13 & 0.82 & 0.62 \\
\hline L20-0 & 450 & 857 & 3.56 & 36 & 2.23 & 37 & 232 & 0.12 & 0.83 & 0.59 \\
\hline M20-0 & 450 & 405 & 3.77 & 35 & 2.36 & 37 & 138 & 0.15 & 0.88 & 0.75 \\
\hline S20-0 & 450 & 188 & 4.05 & 35 & 2.54 & 37 & 74 & 0.17 & 0.84 & 0.87 \\
\hline S-1 & 150 & 180 & 5.56 & 19 & 1.26 & 200 & 18 & 0.20 & 0.78 & 0.90 \\
\hline Series I-1 & 150 & 175 & 5.71 & 19 & 0.90 & 115 & 20 & 0.16 & 1.04 & 1.00 \\
\hline Series I-2 & 150 & 175 & 5.71 & 19 & 0.90 & 115 & 20 & 0.16 & 1.07 & 1.02 \\
\hline Series I-3 & 150 & 175 & 5.71 & 19 & 0.90 & 115 & 20 & 0.16 & 1.07 & 1.02 \\
\hline Series I-4 & 150 & 175 & 5.71 & 19 & 0.90 & 115 & 17 & 0.16 & 0.89 & 0.85 \\
\hline Series I-5 & 150 & 175 & 5.71 & 19 & 0.90 & 115 & 18 & 0.16 & 0.94 & 0.90 \\
\hline Series II-1 & 150 & 175 & 5.71 & 19 & 1.50 & 115 & 26 & 0.18 & 1.24 & 1.33 \\
\hline Series II-2 & 150 & 175 & 5.71 & 19 & 1.50 & 115 & 24 & 0.18 & 1.15 & 1.23 \\
\hline Series II-3 & 150 & 175 & 5.71 & 19 & 1.50 & 115 & 23 & 0.18 & 1.10 & 1.18 \\
\hline Series II-4 & 150 & 175 & 5.71 & 19 & 1.50 & 115 & 23 & 0.18 & 1.10 & 1.18 \\
\hline Series II-5 & 150 & 175 & 5.71 & 19 & 1.50 & 115 & 24 & 0.18 & 1.16 & 1.24 \\
\hline Series III-1 & 150 & 175 & 5.71 & 26 & 0.90 & 115 & 30 & 0.15 & 1.47 & 1.32 \\
\hline Series III-2 & 150 & 175 & 5.71 & 26 & 0.90 & 115 & 27 & 0.15 & 1.34 & 1.21 \\
\hline Series III-3 & 150 & 175 & 5.71 & 26 & 0.90 & 115 & 26 & 0.15 & 1.26 & 1.13 \\
\hline Series III-4 & 150 & 175 & 5.71 & 26 & 0.90 & 115 & 24 & 0.15 & 1.19 & 1.07 \\
\hline Series III-5 & 150 & 175 & 5.71 & 26 & 0.90 & 115 & 22 & 0.15 & 1.09 & 0.98 \\
\hline Series IV-1 & 150 & 175 & 5.71 & 26 & 1.50 & 115 & 30 & 0.17 & 1.31 & 1.31 \\
\hline Series IV-2 & 150 & 175 & 5.71 & 26 & 1.50 & 115 & 29 & 0.17 & 1.27 & 1.27 \\
\hline Series IV-3 & 150 & 175 & 5.71 & 26 & 1.50 & 115 & 24 & 0.17 & 1.08 & 1.08 \\
\hline Series IV-4 & 150 & 175 & 5.71 & 26 & 1.50 & 115 & 28 & 0.17 & 1.25 & 1.26 \\
\hline Series IV-5 & 150 & 175 & 5.71 & 26 & 1.50 & 115 & 25 & 0.17 & 1.09 & 1.09 \\
\hline G-2.5 & 250 & 305 & 2.50 & 40 & 1.55 & 47 & 61 & 0.13 & 1.00 & 0.75 \\
\hline G-2.5-350 & 250 & 296 & 2.50 & 42 & 1.55 & 45 & 71 & 0.12 & 1.18 & 0.87 \\
\hline C- $0.5-350$ & 250 & 310 & 2.50 & 42 & 1.55 & 144 & 59 & 0.16 & 0.73 & 0.68 \\
\hline C-2.5 & 250 & 310 & 2.50 & 35 & 1.55 & 145 & 65 & 0.17 & 0.85 & 0.83 \\
\hline C-2.5-350 & 250 & 310 & 2.50 & 35 & 1.55 & 143 & 73 & 0.17 & 0.95 & 0.94 \\
\hline S-2.5 & 250 & 310 & 2.50 & 49 & 1.55 & 200 & 84 & 0.17 & 0.92 & 0.90 \\
\hline S-2.5-350 & 250 & 308 & 2.50 & 49 & 1.55 & 200 & 106 & 0.17 & 1.18 & 1.16 \\
\hline G-0.5-500 & 250 & 455 & 2.50 & 37 & 1.55 & 46 & 68 & 0.12 & 0.83 & 0.58 \\
\hline G-500 & 250 & 440 & 2.50 & 45 & 1.55 & 47 & 77 & 0.11 & 0.92 & 0.62 \\
\hline G-2.5-500 & 250 & 434 & 2.50 & 37 & 1.55 & 46 & 92 & 0.12 & 1.17 & 0.82 \\
\hline C- $0.5-500$ & 250 & 460 & 2.50 & 42 & 1.55 & 145 & 70 & 0.15 & 0.64 & 0.55 \\
\hline C-500 & 250 & 460 & 2.50 & 42 & 1.55 & 144 & 74 & 0.15 & 0.68 & 0.58 \\
\hline C-2.5-500 & 250 & 439 & 2.50 & 42 & 1.55 & 145 & 83 & 0.15 & 0.78 & 0.68 \\
\hline S-500 & 250 & 458 & 2.50 & 42 & 1.55 & 200 & 111 & 0.16 & 0.95 & 0.88 \\
\hline S-2.5-500 & 250 & 458 & 2.50 & 42 & 1.55 & 200 & 111 & 0.16 & 0.95 & 0.89 \\
\hline B1 & 300 & 200 & 3.50 & 52 & 0.35 & 114 & 64 & 0.12 & 1.23 & 0.87 \\
\hline
\end{tabular}




\begin{tabular}{|c|c|c|c|c|c|c|c|c|c|c|}
\hline Beam label & $\begin{array}{c}b_{w} \\
(\mathrm{~mm})\end{array}$ & $\begin{array}{c}d \\
(\mathrm{~mm})\end{array}$ & $a / d$ & $\begin{array}{c}f_{c}^{\prime} \\
(M P a)\end{array}$ & $\begin{array}{c}\rho_{l} \\
(\%)\end{array}$ & $\begin{array}{c}E_{l} \\
(G P a)\end{array}$ & $\begin{array}{c}V \\
(k N)\end{array}$ & $\beta_{N}$ & $\left(\frac{V_{\text {exp. }}}{V_{\text {ana. }}}\right)$ & $\left(\frac{V_{\text {exp. }}}{V_{\text {ana. }}}\right)_{A C I}$ \\
\hline B2 & 300 & 300 & 3.50 & 52 & 0.32 & 114 & 61 & 0.11 & 0.88 & 0.55 \\
\hline B3 & 300 & 400 & 3.50 & 52 & 0.30 & 114 & 55 & 0.10 & 0.64 & 0.37 \\
\hline B4 & 300 & 500 & 3.50 & 52 & 0.28 & 114 & 68 & 0.09 & 0.67 & 0.37 \\
\hline B5 & 300 & 400 & 6.50 & 52 & 0.30 & 114 & 51 & 0.10 & 0.59 & 0.35 \\
\hline B6 & 300 & 400 & 6.00 & 52 & 0.30 & 114 & 62 & 0.10 & 0.72 & 0.42 \\
\hline G-350-70 & 250 & 291 & 2.50 & 65 & 0.87 & 46 & 76 & 0.10 & 1.27 & 0.76 \\
\hline G-500-70 & 250 & 442 & 2.50 & 74 & 1.25 & 48 & 116 & 0.10 & 1.25 & 0.72 \\
\hline G-650-70 & 300 & 578 & 2.50 & 74 & 1.37 & 48 & 155 & 0.10 & 1.06 & 0.61 \\
\hline C-350-70 & 250 & 310 & 2.50 & 65 & 0.43 & 138 & 72 & 0.11 & 1.05 & 0.67 \\
\hline C-500-70 & 250 & 449 & 2.50 & 74 & 0.68 & 144 & 100 & 0.11 & 0.96 & 0.61 \\
\hline C-650-70 & 300 & 594 & 2.50 & 74 & 0.64 & 144 & 146 & 0.10 & 0.91 & 0.56 \\
\hline G-350 & 250 & 305 & 2.50 & 40 & 1.55 & 47 & 61 & 0.13 & 1.00 & 0.75 \\
\hline C-350 & 250 & 310 & 2.50 & 45 & 1.55 & 145 & 77 & 0.16 & 0.94 & 0.88 \\
\hline S-350 & 250 & 310 & 2.50 & 37 & 1.55 & 200 & 104 & 0.18 & 1.24 & 1.29 \\
\hline G-500 & 250 & 440 & 2.50 & 37 & 1.55 & 47 & 129 & 0.12 & 1.62 & 1.13 \\
\hline C-500 & 250 & 460 & 2.50 & 35 & 1.55 & 144 & 65 & 0.15 & 0.62 & 0.56 \\
\hline S-500 & 250 & 458 & 2.50 & 42 & 1.55 & 200 & 74 & 0.16 & 0.63 & 0.58 \\
\hline G-650 & 300 & 584 & 2.50 & 37 & 1.55 & 46 & 113 & 0.12 & 0.91 & 0.62 \\
\hline C-650 & 300 & 594 & 2.50 & 42 & 1.55 & 147 & 139 & 0.14 & 0.83 & 0.70 \\
\hline S-650 & 300 & 608 & 2.50 & 49 & 1.55 & 200 & 84 & 0.15 & 0.44 & 0.38 \\
\hline G-800 & 300 & 734 & 2.40 & 42 & 1.55 & 47 & 111 & 0.11 & 0.73 & 0.46 \\
\hline C-800 & 300 & 744 & 2.40 & 42 & 1.55 & 145 & 156 & 0.14 & 0.78 & 0.63 \\
\hline S-800 & 300 & 758 & 2.40 & 42 & 1.55 & 200 & 200 & 0.15 & 0.92 & 0.80 \\
\hline B-400-2 & 200 & 368 & 2.70 & 23 & 1.55 & 141 & 33 & 0.17 & 0.56 & 0.55 \\
\hline B-400-4 & 200 & 368 & 2.70 & 23 & 1.55 & 141 & 36 & 0.17 & 0.61 & 0.60 \\
\hline B-300-2 & 200 & 276 & 3.60 & 30 & 1.55 & 141 & 33 & 0.17 & 0.65 & 0.64 \\
\hline B-300-4 & 200 & 276 & 3.60 & 30 & 1.55 & 141 & 33 & 0.17 & 0.65 & 0.64 \\
\hline B-200-2 & 200 & 170 & 5.90 & 25 & 1.55 & 141 & 18 & 0.19 & 0.54 & 0.61 \\
\hline B-200-4 & 200 & 170 & 5.90 & 25 & 1.55 & 141 & 21 & 0.19 & 0.63 & 0.72 \\
\hline I-No.1 & 150 & 250 & 3.00 & 34 & 1.51 & 105 & 45 & 0.15 & 1.41 & 1.21 \\
\hline II-No.6 & 150 & 250 & 3.00 & 34 & 3.03 & 105 & 46 & 0.17 & 1.24 & 1.23 \\
\hline IV-No.15 & 150 & 250 & 3.00 & 34 & 2.27 & 105 & 41 & 0.16 & 1.16 & 1.08 \\
\hline $8-2-1$ & 127 & 143 & 6.36 & 55 & 0.33 & 139 & 14 & 0.11 & 0.98 & 0.63 \\
\hline $8-2-2$ & 127 & 143 & 6.36 & 55 & 0.33 & 139 & 13 & 0.11 & 0.88 & 0.56 \\
\hline $8-2-3$ & 127 & 143 & 6.36 & 55 & 0.33 & 139 & 15 & 0.11 & 1.00 & 0.64 \\
\hline $8-3-1$ & 159 & 141 & 6.45 & 55 & 0.58 & 139 & 20 & 0.13 & 0.92 & 0.70 \\
\hline $8-3-2$ & 159 & 141 & 6.45 & 55 & 0.58 & 139 & 23 & 0.13 & 1.07 & 0.82 \\
\hline $8-3-3$ & 159 & 141 & 6.45 & 55 & 0.58 & 139 & 17 & 0.13 & 0.79 & 0.60 \\
\hline $11-2-1$ & 89 & 143 & 6.36 & 76 & 0.47 & 139 & 9 & 0.10 & 0.78 & 0.46 \\
\hline $11-2-2$ & 89 & 143 & 6.36 & 76 & 0.47 & 139 & 12 & 0.10 & 1.04 & 0.62 \\
\hline $11-2-3$ & 89 & 143 & 6.36 & 76 & 0.47 & 139 & 9 & 0.10 & 0.79 & 0.47 \\
\hline $11-3-1$ & 121 & 141 & 6.45 & 76 & 0.76 & 139 & 14 & 0.12 & 0.80 & 0.57 \\
\hline $11-3-2$ & 121 & 141 & 6.45 & 76 & 0.76 & 139 & 15 & 0.12 & 0.85 & 0.61 \\
\hline $11-3-3$ & 121 & 141 & 6.45 & 76 & 0.76 & 139 & 17 & 0.12 & 0.92 & 0.65 \\
\hline C-L-18-R1-1,2 & 200 & 216 & 3.10 & 34 & 0.30 & 146 & 26 & 0.12 & 0.86 & 0.61 \\
\hline C-L-18-R2-1,2 & 150 & 216 & 3.10 & 34 & 0.39 & 146 & 19 & 0.12 & 0.84 & 0.59 \\
\hline C-L-18-R3-1,2 & 150 & 214 & 3.10 & 34 & 0.83 & 148 & 15 & 0.14 & 0.58 & 0.48 \\
\hline C-L-27-R1-1,2 & 200 & 216 & 3.10 & 40 & 0.30 & 146 & 23 & 0.12 & 0.73 & 0.50 \\
\hline C-L-27-R2-1,2 & 150 & 216 & 3.10 & 40 & 0.39 & 146 & 21 & 0.12 & 0.89 & 0.60 \\
\hline C-L-27-R3-1,2 & 150 & 214 & 3.10 & 40 & 0.83 & 148 & 26 & 0.14 & 0.94 & 0.76 \\
\hline G-L-18-R1-1,2 & 200 & 216 & 3.10 & 34 & 0.30 & 41 & 21 & 0.09 & 0.91 & 0.49 \\
\hline
\end{tabular}




\begin{tabular}{|c|c|c|c|c|c|c|c|c|c|c|}
\hline Beam label & $\begin{array}{c}b_{w} \\
(\mathrm{~mm})\end{array}$ & $\begin{array}{c}d \\
(\mathrm{~mm})\end{array}$ & $a / d$ & $\begin{array}{c}f_{c}^{\prime} \\
(M P a)\end{array}$ & $\begin{array}{c}\rho_{l} \\
(\%)\end{array}$ & $\begin{array}{c}E_{l} \\
(G P a)\end{array}$ & $\begin{array}{c}V \\
(k N)\end{array}$ & $\beta_{N}$ & $\left(\frac{V_{\text {exp. }}}{V_{\text {ana. }}}\right)$ & $\left(\frac{V_{\text {exp. }}}{V_{\text {ana. }}}\right)_{A C I}$ \\
\hline G-L-18-R2-1,2 & 150 & 216 & 3.10 & 34 & 0.39 & 41 & 19 & 0.09 & 1.09 & 0.58 \\
\hline G-L-18-R3-1,2 & 150 & 214 & 3.10 & 34 & 0.83 & 40 & 15 & 0.11 & 0.77 & 0.48 \\
\hline G-L-27-R1-1,2 & 200 & 216 & 3.10 & 40 & 0.30 & 41 & 20 & 0.09 & 0.85 & 0.44 \\
\hline G-L-27-R2-1,2 & 150 & 215.5 & 3.10 & 40 & 0.39 & 41 & 20 & 0.09 & 1.11 & 0.57 \\
\hline G-L-27-R3-1,2 & 150 & 213.5 & 3.10 & 40 & 0.83 & 40 & 22 & 0.10 & 1.03 & 0.62 \\
\hline A1 & 457 & 889 & 3.1 & 30 & 0.59 & 41 & 159 & 0.10 & 0.75 & 0.42 \\
\hline V-S-1 & 457 & 360 & 3.4 & 41 & 0.96 & 200 & 181 & 0.17 & 1.00 & 1.01 \\
\hline V-G1-1 & 457 & 360 & 3.4 & 40 & 0.96 & 41 & 109 & 0.12 & 0.86 & 0.62 \\
\hline V-G2-1 & 457 & 360 & 3.4 & 40 & 0.96 & 38 & 95 & 0.12 & 0.77 & 0.54 \\
\hline V-A-1 & 457 & 360 & 3.4 & 40 & 0.96 & 47 & 116 & 0.13 & 0.88 & 0.65 \\
\hline V-S-2 & 457 & 360 & 3.4 & 41 & 1.92 & 200 & 205 & 0.20 & 0.97 & 1.14 \\
\hline V-D-2 & 457 & 360 & 3.4 & 44 & 0.36 & 200 & 136 & 0.14 & 0.91 & 0.73 \\
\hline V-G1-2 & 457 & 360 & 3.4 & 42 & 1.92 & 41 & 138 & 0.14 & 0.92 & 0.76 \\
\hline V-G2-2 & 457 & 360 & 3.4 & 43 & 1.92 & 38 & 154 & 0.14 & 1.04 & 0.84 \\
\hline V-A-2 & 457 & 360 & 3.4 & 43 & 1.92 & 47 & 178 & 0.14 & 1.15 & 0.98 \\
\hline S1-0.12-SB & 457 & 883 & 3.10 & 30 & 0.59 & 41 & 254 & 0.10 & 1.20 & 0.68 \\
\hline S3-0.24-1B & 114 & 292 & 3.10 & 41 & 1.18 & 48 & 22 & 0.10 & 1.02 & 0.61 \\
\hline S3-0.24-2B & 114 & 292 & 3.10 & 41 & 1.18 & 48 & 21 & 0.10 & 0.95 & 0.57 \\
\hline S6-0.24-1B & 229 & 146 & 3.10 & 41 & 1.18 & 48 & 33 & 0.14 & 1.12 & 0.91 \\
\hline S6-0.24-2B & 229 & 146 & 3.10 & 41 & 1.18 & 48 & 33 & 0.14 & 1.10 & 0.90 \\
\hline G-512-30-15 & 150 & 379 & 2.90 & 30 & 0.99 & 52 & 34 & 0.11 & 1.03 & 0.65 \\
\hline G-316-30-15 & 150 & 377 & 2.92 & 29 & 1.07 & 52 & 32 & 0.11 & 0.96 & 0.62 \\
\hline G-318-30-15 & 150 & 376 & 2.93 & 29 & 1.35 & 52 & 39 & 0.12 & 1.11 & 0.75 \\
\hline G-416-30-15 & 150 & 377 & 2.92 & 31 & 1.42 & 52 & 35 & 0.12 & 0.97 & 0.65 \\
\hline G-418-30-15 & 150 & 376 & 2.93 & 29 & 1.80 & 52 & 38 & 0.12 & 1.03 & 0.74 \\
\hline G-312/212-30-15 & 150 & 368 & 2.99 & 32 & 1.02 & 52 & 35 & 0.11 & 1.05 & 0.66 \\
\hline G-318/118-30-15 & 150 & 367 & 3.00 & 32 & 1.85 & 52 & 48 & 0.12 & 1.27 & 0.91 \\
\hline G-512-30-35 & 150 & 359 & 3.06 & 29 & 1.05 & 52 & 32 & 0.11 & 1.02 & 0.66 \\
\hline G-316-30-35 & 150 & 357 & 3.08 & 31 & 1.13 & 52 & 31 & 0.11 & 0.95 & 0.62 \\
\hline G-318-30-35 & 150 & 356 & 3.09 & 31 & 1.43 & 52 & 34 & 0.12 & 1.00 & 0.69 \\
\hline G-418-30-35 & 150 & 356 & 3.09 & 30 & 1.91 & 52 & 39 & 0.12 & 1.08 & 0.79 \\
\hline 4A3 & 203 & 390 & 4.69 & 31 & 2.06 & 200 & 110 & 0.18 & 1.41 & 1.47 \\
\hline $11 \mathrm{~A} 2$ & 152 & 314 & 5.83 & 30 & 3.41 & 200 & 73 & 0.20 & 1.42 & 1.64 \\
\hline 12A2 & 152 & 238 & 7.69 & 30 & 4.50 & 200 & 64 & 0.22 & 1.45 & 1.90 \\
\hline 18A2 & 152 & 316 & 5.79 & 19 & 2.68 & 200 & 63 & 0.21 & 1.45 & 1.76 \\
\hline 18B2 & 152 & 316 & 5.79 & 20 & 2.68 & 200 & 72 & 0.20 & 1.64 & 1.98 \\
\hline $18 \mathrm{C} 2$ & 152 & 316 & 5.79 & 23 & 2.68 & 200 & 73 & 0.20 & 1.61 & 1.89 \\
\hline 18D2 & 152 & 316 & 5.79 & 22 & 2.68 & 200 & 60 & 0.20 & 1.33 & 1.56 \\
\hline $13 \mathrm{~A} 2$ & 152 & 319 & 5.73 & 20 & 0.80 & 200 & 48 & 0.16 & 1.43 & 1.31 \\
\hline 14A2 & 152 & 243 & 7.53 & 21 & 1.05 & 200 & 35 & 0.17 & 1.20 & 1.23 \\
\hline $15 \mathrm{~A} 2$ & 152 & 316 & 5.79 & 20 & 1.34 & 200 & 46 & 0.17 & 1.21 & 1.25 \\
\hline 15B2 & 152 & 316 & 5.79 & 21 & 3.14 & 200 & 52 & 0.21 & 1.13 & 1.40 \\
\hline $16 \mathrm{~A} 2$ & 152 & 240 & 7.62 & 22 & 1.77 & 200 & 42 & 0.19 & 1.26 & 1.43 \\
\hline $17 \mathrm{~A} 2$ & 152 & 243 & 7.53 & 22 & 2.09 & 200 & 44 & 0.20 & 1.27 & 1.49 \\
\hline 18E2 & 152 & 316 & 5.79 & 20 & 2.68 & 200 & 82 & 0.20 & 1.87 & 2.25 \\
\hline 19A2 & 152 & 240 & 7.62 & 21 & 3.53 & 200 & 46 & 0.23 & 1.22 & 1.64 \\
\hline $20 \mathrm{~A} 2$ & 152 & 238 & 7.69 & 21 & 4.52 & 200 & 51 & 0.24 & 1.27 & 1.80 \\
\hline $21 \mathrm{~A} 2$ & 203 & 238 & 7.69 & 20 & 5.01 & 200 & 77 & 0.27 & 1.34 & 2.09 \\
\hline $2 \mathrm{AC}$ & 152 & 254 & 9.6 & 23 & 1.32 & 200 & 38 & 0.18 & 1.15 & 1.20 \\
\hline $3 \mathrm{AC}$ & 152 & 256 & 9.54 & 21 & 1.99 & 200 & 44 & 0.20 & 1.25 & 1.46 \\
\hline $4 \mathrm{AC}$ & 152 & 254 & 9.6 & 16 & 2.63 & 200 & 38 & 0.22 & $\begin{array}{l}1.08 \\
\end{array}$ & 1.42 \\
\hline
\end{tabular}




\begin{tabular}{|c|c|c|c|c|c|c|c|c|c|c|}
\hline Beam label & $\begin{array}{c}b_{w} \\
(\mathrm{~mm})\end{array}$ & $\begin{array}{c}d \\
(\mathrm{~mm})\end{array}$ & $a / d$ & $\begin{array}{c}f_{c}^{\prime} \\
(M P a)\end{array}$ & $\begin{array}{c}\rho_{l} \\
(\%)\end{array}$ & $\begin{array}{c}E_{l} \\
(G P a)\end{array}$ & $\begin{array}{c}V \\
(k N)\end{array}$ & $\beta_{N}$ & $\left(\frac{V_{\text {exp. }}}{V_{\text {ana. }}}\right)$ & $\left(\frac{V_{\text {exp. }}}{V_{\text {ana. }}}\right)_{A C I}$ \\
\hline $5 \mathrm{AC}$ & 152 & 252 & 9.66 & 18 & 3.35 & 200 & 42 & 0.23 & 1.11 & 1.49 \\
\hline $6 \mathrm{AC}$ & 152 & 250 & 9.74 & 23 & 4.30 & 200 & 53 & 0.23 & 1.27 & 1.72 \\
\hline $3 \mathrm{CC}$ & 152 & 256 & 11.92 & 20 & 1.99 & 200 & 36 & 0.20 & 1.01 & 1.19 \\
\hline $4 \mathrm{CC}$ & 152 & 254 & 12 & 21 & 2.63 & 200 & 40 & 0.21 & 1.08 & 1.34 \\
\hline $5 \mathrm{CC}$ & 152 & 252 & 12.07 & 20 & 3.35 & 200 & 44 & 0.22 & 1.14 & 1.51 \\
\hline $6 \mathrm{CC}$ & 152 & 250 & 12.17 & 21 & 4.30 & 200 & 44 & 0.24 & 1.09 & 1.51 \\
\hline 4EC & 152 & 254 & 14.4 & 21 & 2.63 & 200 & 42 & 0.21 & 1.11 & 1.38 \\
\hline $5 \mathrm{EC}$ & 152 & 252 & 14.48 & 19 & 3.35 & 200 & 40 & 0.23 & 1.03 & 1.37 \\
\hline $6 \mathrm{EC}$ & 152 & 250 & 14.6 & 19 & 4.30 & 200 & 42 & 0.24 & 1.05 & 1.49 \\
\hline $4 \mathrm{GC}$ & 152 & 254 & 16.8 & 21 & 2.63 & 200 & 37 & 0.21 & 0.99 & 1.22 \\
\hline $5 \mathrm{GC}$ & 152 & 252 & 16.9 & 22 & 3.35 & 200 & 42 & 0.22 & 1.05 & 1.37 \\
\hline \multirow[t]{4}{*}{$6 \mathrm{GC}$} & 152 & 250 & 17.03 & 21 & 4.30 & 200 & 40 & 0.23 & 0.98 & 1.35 \\
\hline & & & & & & & & Aver. & 1.05 & 0.91 \\
\hline & & & & & & & & SD & 0.25 & 0.39 \\
\hline & & & & & & & & $\mathrm{COV}$ & $23.8 \%$ & $42 \%$ \\
\hline
\end{tabular}


Table 3. Demerit points classification criteria

\begin{tabular}{|l|l|c|}
\hline$\lambda=V_{\text {exp. }} / \mathrm{V}_{\text {ana. }}$ & Classification & Penalty \\
\hline$<0.5$ & Extremely Dangerous & 10 \\
\hline$[0.5-0.85[$ & Dangerous & 5 \\
\hline$[0.85-1.15[$ & Appropriate Safety & 0 \\
\hline$[1.15-2[$ & Conservative & 1 \\
\hline$\geq 2.0$ & Extremely Conservative & 2 \\
\hline
\end{tabular}

Table 4. Predictive performance of different approaches according to the modified version of the DPC on DB

\begin{tabular}{|c|c|c|c|c|}
\hline \multirow{2}{*}{$\lambda=V_{\text {exp. }} / \mathrm{V}_{\text {ana. }}$} & \multicolumn{2}{|c|}{ Equation (9) } & \multicolumn{2}{c|}{ ACI model } \\
\cline { 2 - 5 } & $\begin{array}{c}N^{o} \\
\text { samples }\end{array}$ & Total & $\begin{array}{c}N^{o} \\
\text { samples }\end{array}$ & Total \\
\hline$<0.5$ & 1 & 10 & 17 & 170 \\
\hline$[0.5-0.85[$ & 40 & 200 & 99 & 495 \\
\hline$[0.85-1.15[$ & 111 & 0 & 44 & 0 \\
\hline$[1.15-2[$ & 62 & 62 & 52 & 52 \\
\hline$\geq 2.0$ & 1 & 2 & 3 & 6 \\
\hline$\sum$ & 216 & 274 & 216 & 723 \\
\hline
\end{tabular}

Table 5. Predictive performance of different approaches according to the modified version of the DPC on RDB

\begin{tabular}{|c|c|c|c|c|}
\hline \multirow{2}{*}{$\lambda=V_{\text {exp. }} / \mathrm{V}_{\text {ana. }}$} & \multicolumn{2}{|c|}{ Equation (9) } & \multicolumn{2}{c|}{ ACI model } \\
\cline { 2 - 5 } & $\begin{array}{c}N^{o} \\
\text { samples }\end{array}$ & Total & $\begin{array}{c}N^{o} \\
\text { samples }\end{array}$ & Total \\
\hline$<0.5$ & 0 & 0 & 0 & 0 \\
\hline$[0.5-0.85[$ & 2 & 10 & 61 & 305 \\
\hline$[0.85-1.15[$ & 83 & 0 & 40 & 0 \\
\hline$[1.15-2[$ & 60 & 60 & 43 & 43 \\
\hline$\geq 2.0$ & 0 & 0 & 1 & 2 \\
\hline$\sum$ & 145 & 70 & 145 & 350 \\
\hline
\end{tabular}




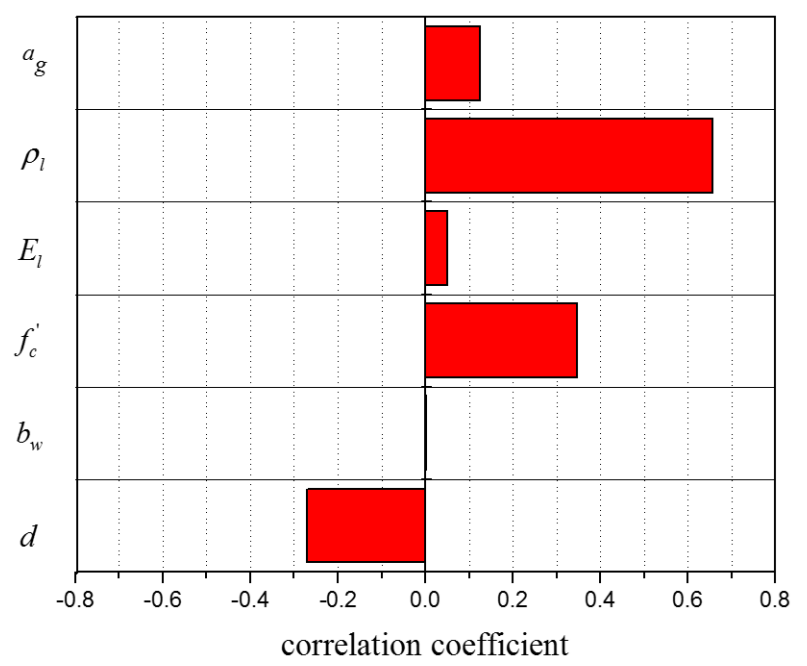

a)

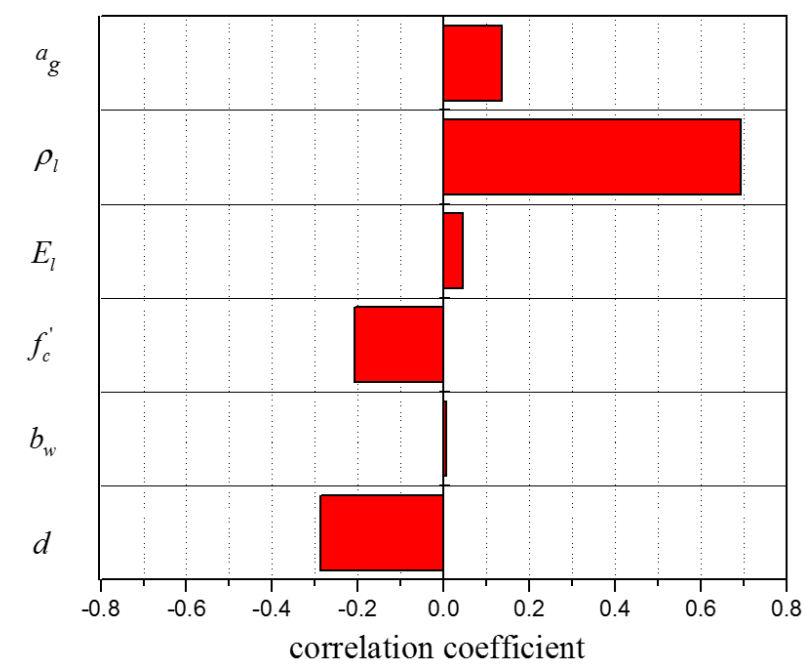

b)

Figure 1: Sensitivity analysis for (a) SMCFT; (b) the tensile stress in the cracked concrete $(\beta)$ 


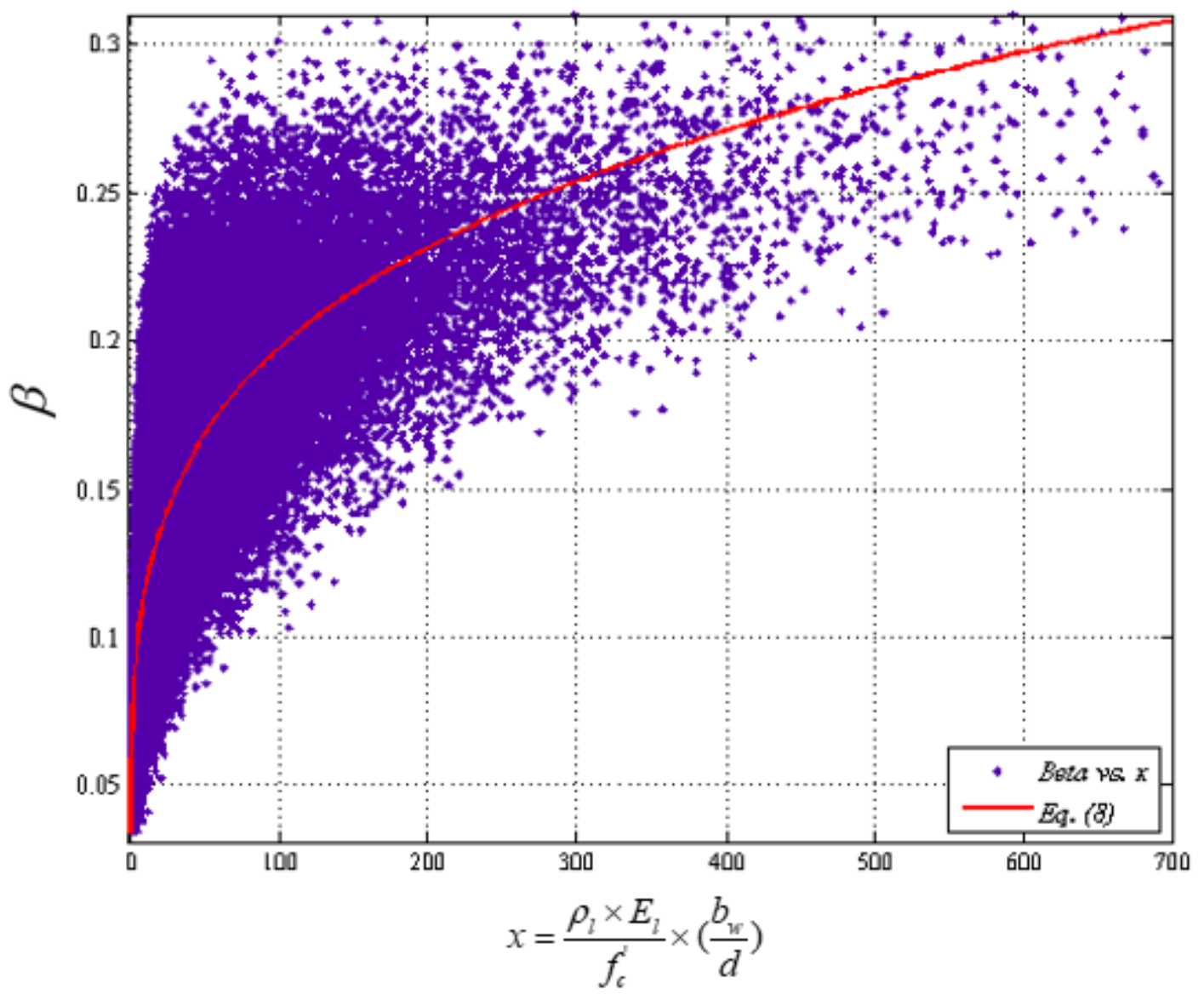

Figure 2. Results of Monte Carlo simulation 

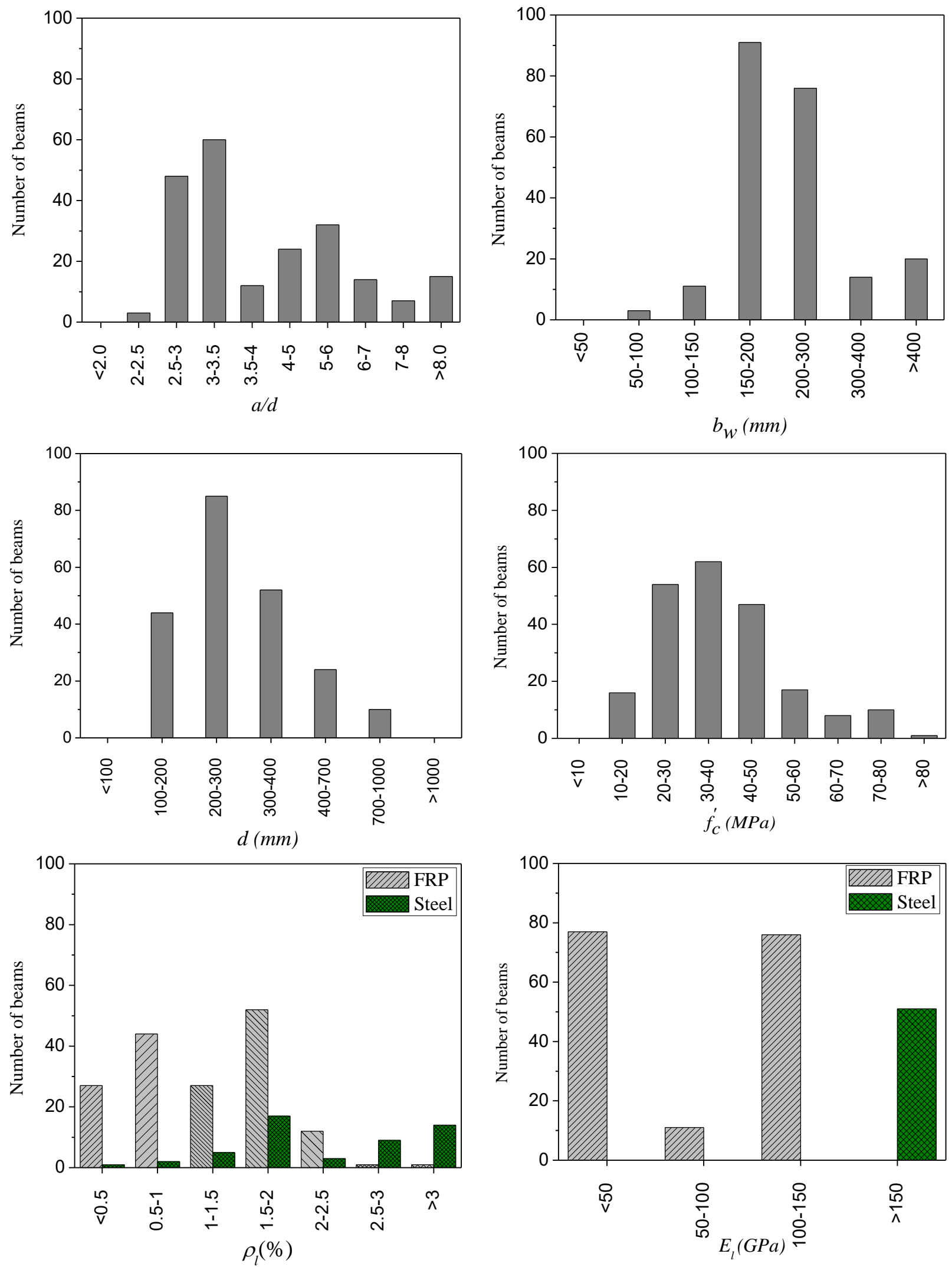

Figure 3: Distribution of the variables used in data base (DB) 


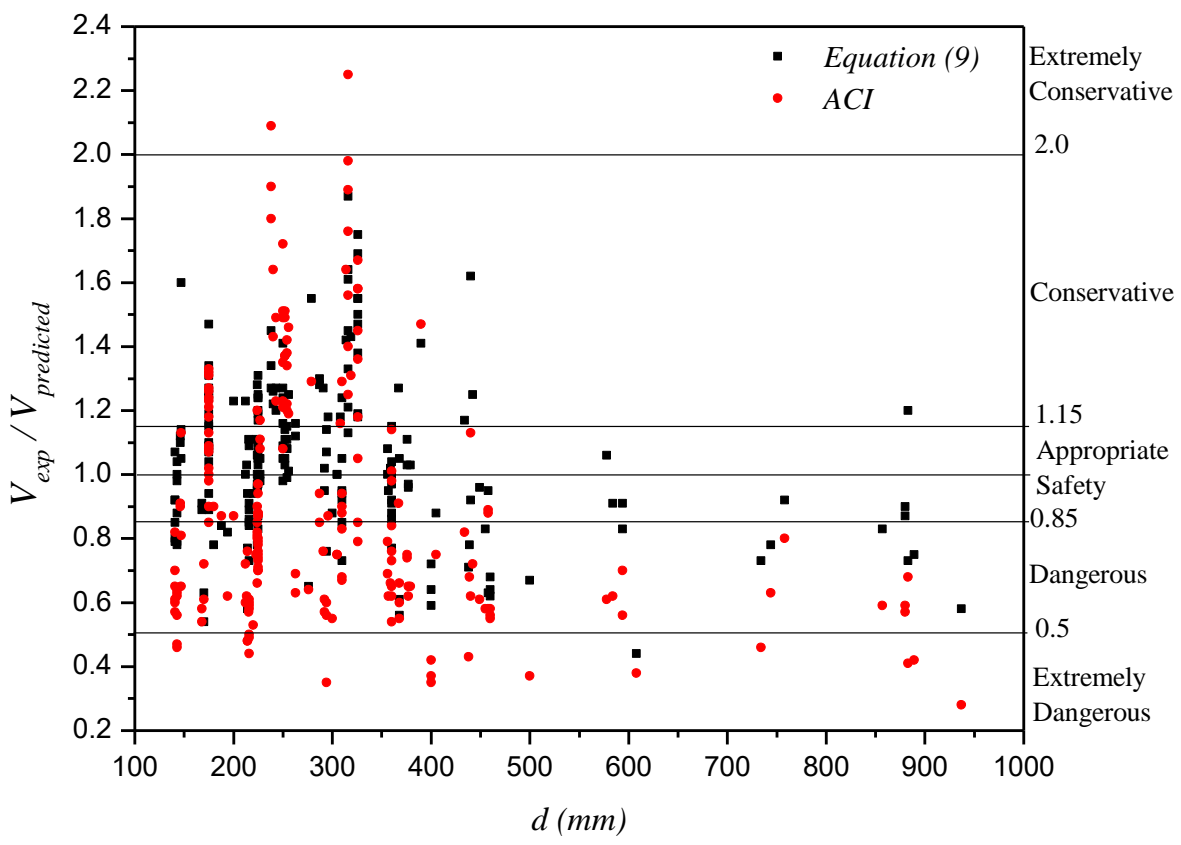

Figure 4. Ratio of experimental to analytical model 


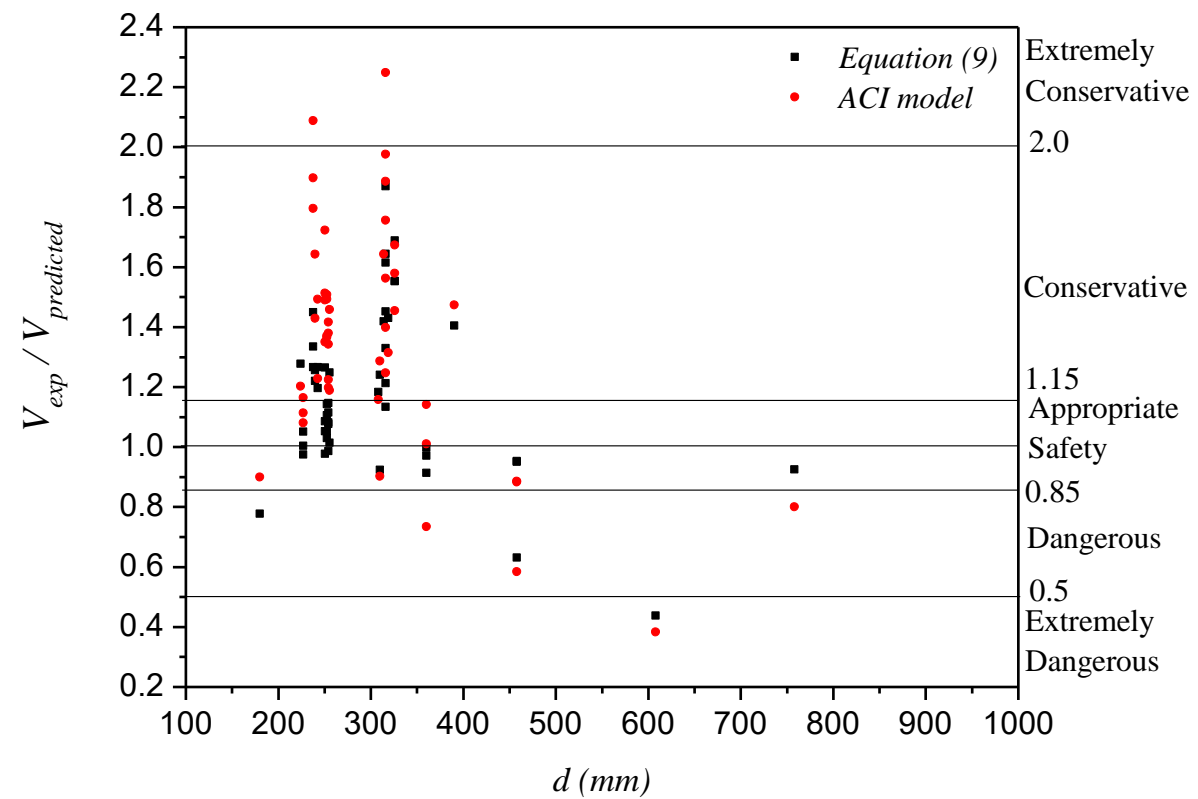

a) steel

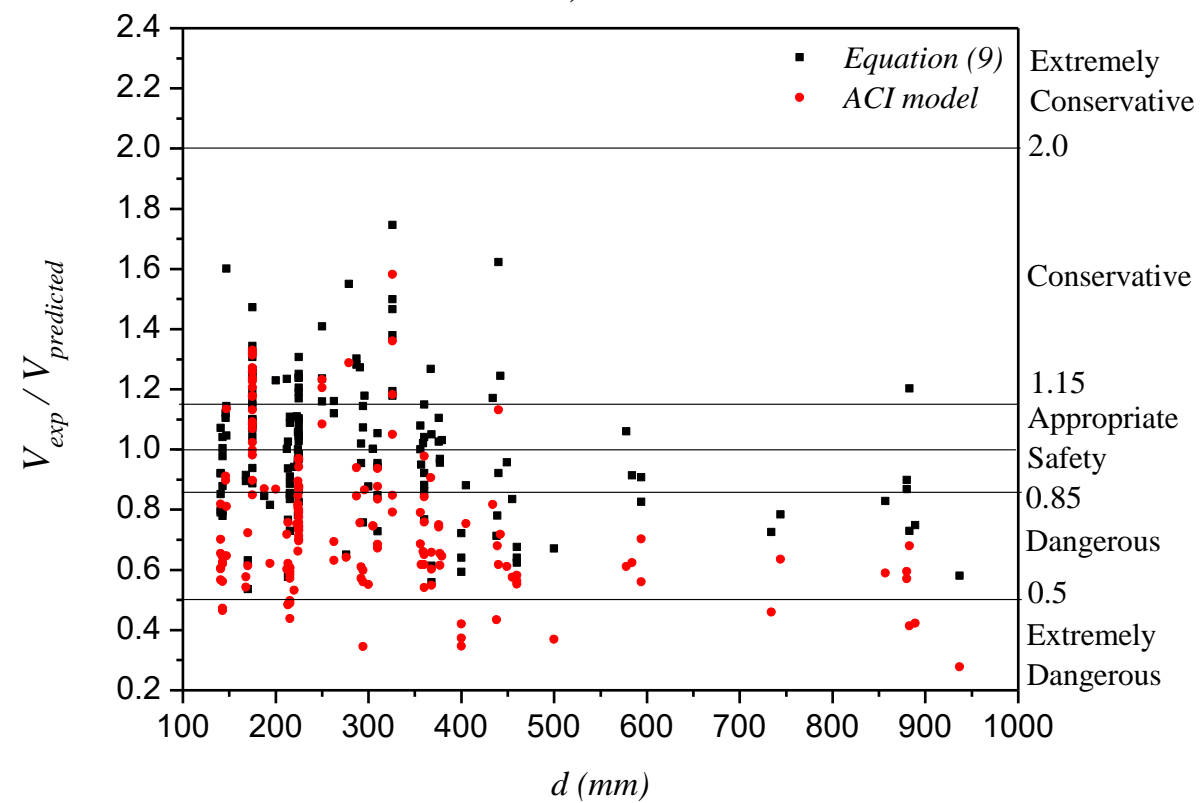

b) FRP

Figure 5. Ratio of experimental to analytical model for the beams with a) Steel and b) FRP longitudinal reinforcement 


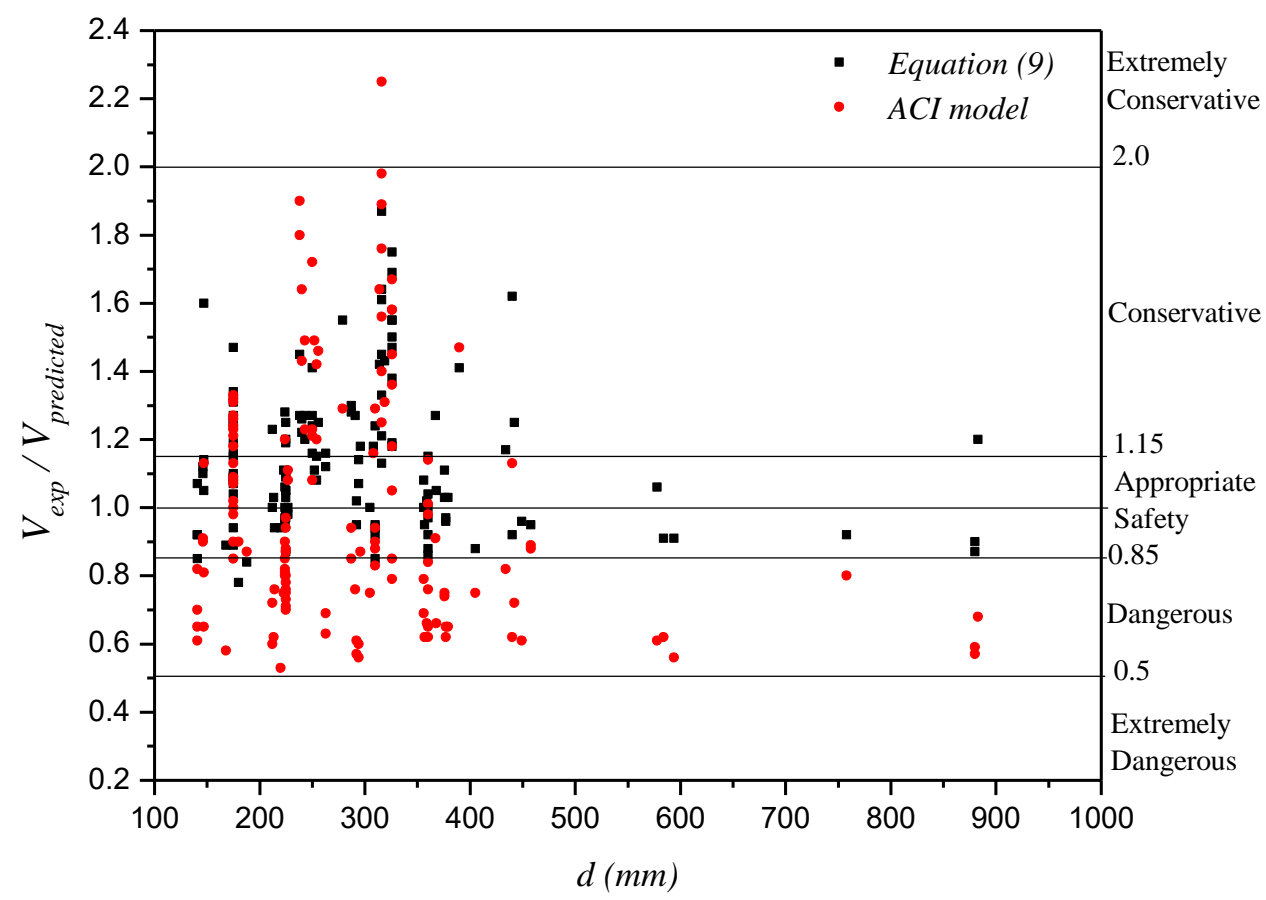

Figure 6: Values of the experimental vs. analytical ratio, considering the results from the RDB 